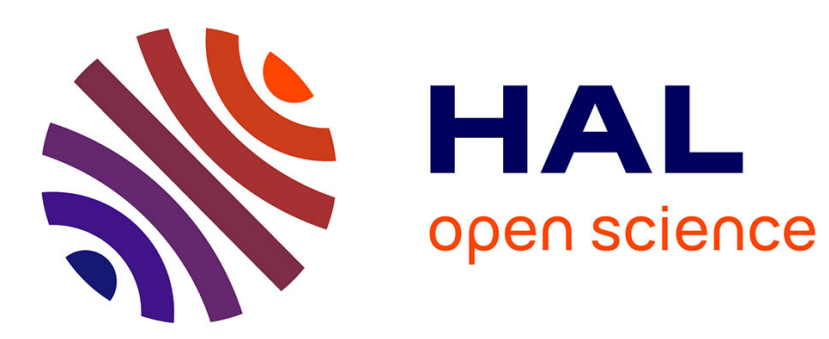

\title{
Social Distance and Parochial Altruism: An Experimental Study
}

Béatrice Boulu-Reshef, Jonah Schulhofer-Wohl

\section{To cite this version:}

Béatrice Boulu-Reshef, Jonah Schulhofer-Wohl. Social Distance and Parochial Altruism: An Experimental Study. 2019. hal-02135633

\section{HAL Id: hal-02135633 \\ https://hal.science/hal-02135633}

Preprint submitted on 21 May 2019

HAL is a multi-disciplinary open access archive for the deposit and dissemination of scientific research documents, whether they are published or not. The documents may come from teaching and research institutions in France or abroad, or from public or private research centers.
L'archive ouverte pluridisciplinaire HAL, est destinée au dépôt et à la diffusion de documents scientifiques de niveau recherche, publiés ou non, émanant des établissements d'enseignement et de recherche français ou étrangers, des laboratoires publics ou privés. 


\title{
Social Distance and Parochial Altruism: An Experimental Study
}

\author{
Béatrice Boulu-Reshef and Jonah Schulhofer-Wohl ${ }^{\ddagger}$
}

Parochial altruism - individual sacrifice to benefit the in-group and harm an out-group undermines inter-group cooperation and is implicated in a plethora of politically-significant behaviors. We report new experimental findings about the impact of variation in social distance within the in-group together with variation in social distance between the in- and out-groups on parochial altruism. Building from a minimal group paradigm set-up, we find that differential social distance has a systematic effect on individual choice in a setting of potential inter-group conflict. In particular, parochial altruism is stimulated when individuals' distance to both their in- and out-group is high. A long-standing finding about behavior in contexts of inter-group conflict is that low social distance facilitates collective action. Our results suggest that the effects of high social distance may create a potential additional pathway to group-based individual action. Research on inter-group conflict and collective action can be advanced by investigating such effects.

* Université Paris 1 Panthéon-Sorbonne, Centre d'Economie de la Sorbonne. E-mail:

beatrice.boulu-reshef@univ-parisl.fr.

$\ddagger$ University of Virginia, Department of Politics, and John F. Kennedy School of Government, Harvard University. E-mail: jsw@hks. harvard.edu. 


\section{Introduction}

Cooperation is critical to the success of myriad human activities, all the more so in complex societies. Yet parochial altruism - defined as individual sacrifice to benefit the in-group and harm an outgroup - is an ingrained behavior that undermines inter-group cooperation and causes inter-group conflict (Bernhard et al. 2006; Choi \& Bowles 2007; De Dreu et al. 2010; Ten Velden et al. 2017; Ma et al 2015; Filippin \& Guala 2017; De Dreu 2012). Indeed, the long-standing literature on fractionalization (Alesina et al. 2003), which studies the effects of diversity and heterogeneity on development and cooperation, documents the role of in-group cooperation and out-group conflict as central mechanisms that lead to resource depletion (Easterly and Levine 1997; Alesina et al. 1999; Habyarimana et al. 2007; Keuschnigg and Schikora 2014). As contemporary societies experience transformative change due to growth in the population share of minority groups through inter-group fertility differences, immigration, and the infusion of refugees, the detrimental effects of parochial altruism bite all the more deeply (Dinesen \& Sønderskov 2015; Enos 2017; McCoy et al. 2018; Rueda 2017).

Research has productively investigated parochial altruism's evolutionary origins (Bernhard et al. 2006; Choi \& Bowles 2007; Boehm 2012) and neurobiological mechanisms (De Dreu 2012; Kavaliers \& Choleris 2017). Yet questions at the heart of applied research on cooperation and conflict cannot be answered solely through a better understanding of parochial altruism's neurobiological bases. Instead, it is clear that the social environment in which individuals act is of critical importance (Alesina et. al. 1999; Petersen 2001; Huettel \& Kranton 2012; Sambanis et. al. 2012;).

Existing research assumes an integral and specific role of distance for in-group cooperation and inter-group conflict: individuals within close-knit in-groups are more likely to behave altruistically, and are more likely to behave parochially towards an out-group that constitutes a threat due to its proximity to the in-group (Hardin 1995).

We report findings from a new study through which we begin to examine the multifaceted nature 
of social distance empirically. We employed a novel experimental technique to study the relationship between the extent of the inter-group divide and parochial altruism, introducing real social identity subtly into a minimal group paradigm (MGP) experimental set-up. Our experimental set-up permits us to investigate the impact of variation in social distance within the in-group together with variation in social distance between the in- and out-groups. We found that differential social distance has a systematic effect on individual choice in a setting of potential inter-group conflict. In particular, parochial altruism was stimulated when individuals' distance to both their in- and out-group was high.

The results call into question that long-standing assumption about behavior within the ingroup/out-group dyad and point to the need for research on inter-group conflict to develop a more nuanced understanding of the role of social distance. By experimentally testing the effects of sociallyrelevant distance on parochial behavior, our research contributes to assembling a body of causal evidence on the natural experience of parochial altruism. Our findings help to build knowledge on the impact of combinations of in- and out-group social distance. They also motivate further study of parochial altruism using socially-, and therefore politically-relevant identity categories, in particular, investigation of the effects of the extent of the inter-group divide and the differential impact of various types of identity categories.

\section{Method}

Dominant models of experimental research on parochial altruism face external validity challenges that hamper their ability to investigate the effects of inter-group divides (Huettel \& Kranton 2012; Goette, et. al. 2012). MGP experimental designs eliminate potential barriers to inference by inducing group identity using arbitrary, socially irrelevant groups (Tajfel et al. 1971) and establish parochial altruism's presence in inter-group settings. But their ability to evaluate which types of inter-group relations parochial altruism affects and how effects may depend on characteristics of the inter-group divide is limited because they use socially-irrelevant group identities. Lab-in-the-field experiments use researcher-selected social identity, sometimes as fine-grained as sports team allegiance, but typically tribal affiliation, ethnicity, race, religion, 
or language (Bernhard et al. 2006; Weisel \& Böhm 2015; Schaub 2017); findings, however, can be context dependent.

Our experimental methodology attempts to bridge the gap between MGP and lab-in-the-field experiments to study inter-group divisions and parochial altruism in a laboratory setting. We placed subjects in minimal groups, but subsequently provided information about social characteristics of each inand out-group member. The design overcomes the social irrelevance of minimal groups without the labin-the-field model's social specificity through our subtle implementation of social information and use of an abstract type of group divide - social distance, in a basic manifestation, locality of origin. Territory, particularly during times of environmental scarcity, constitutes a basis for inter-individual and inter-group contentious behavior, including homicide and war (Wilson 1978; Manson \& Wrangham 1991; Ember \& Ember 1992; Gat 2006 2015; Pandit et al. 2016; Glowacki et. al.2017). Composition with respect to locality of origin can vary within and between groups. Locality of origin thus has the hallmarks of a social identity.

We used the intergroup prisoner's dilemma-maximizing difference game (Halevy et. al. 2008) (IPD-MD) to study the effects of social distance on parochial altruism. The IPD-MD pits two equal-sized groups against each other. Each player decides how much of her endowment to keep and how much to allocate to two resource pools - one "within-group" (w) and one "between-group" (b). Our implementation followed De Dreu et. al (2010): Each subject received a 10 [currency unit] endowment, every 1 [currency unit] contributed to $w$ increased the pay-off of in-group members including the subject by 0.50 [currency units], every 1 [currency unit] contributed to $b$ increased the pay-off of in-group members including the subject by 0.50 [currency units] and reduced that of out-group members by 0.50 [currency units], and every 1 [currency unit] kept yielded a pay-off of 1.00 [currency unit] (i.e., if kept, it retained its original value).

We conducted the experiment with 294 undergraduate male and female subjects. ${ }^{1}$ In the baseline,

\footnotetext{
1 Table A-1 in the Appendix reports details of the organization of the study.
} 
we implemented an MGP procedure. The treatment modified the baseline by providing each subject information about socially-relevant characteristics of each in- and out-group member, including the subject herself. The treatment also required all subjects to be from [province]. This subject pool restriction limited the social distance measure's range to avoid highly skewed groups

We implemented social distance subtly. Subjects in the treatment condition received an information sheet describing three characteristics of each in- and out-group member: locality of origin (sub-provincial unit), age, and sex. The sheet displayed locality of origin using a GIS map of [province] with sub-provincial boundaries, with group-specific markers placed for each in- and out-group member. The map had no labels and was presented alongside information about sex and age (Fig. 1). Spatial representation and absence of labels make the map less likely to convey any meaning beyond an abstract notion of social distance.

Figure 1: Example information sheet, social distance treatment

[province boundary modified and sub-provincial boundaries removed to preserve anonymity in review process].

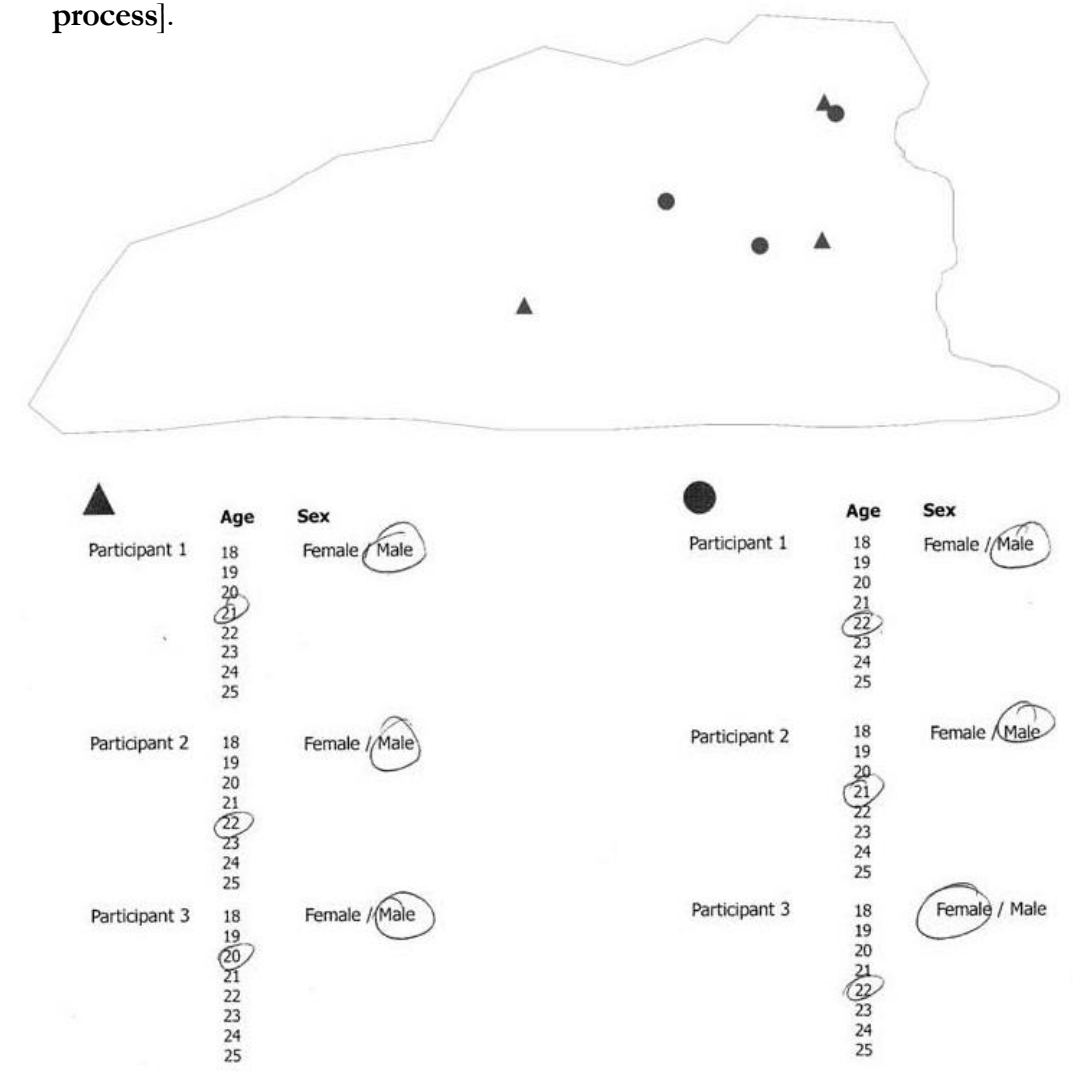




\section{Results}

Aggregate outcomes in our study align with the literature: subjects kept the largest portion of their endowment, allocated a smaller portion to $w$, and an even smaller portion to $b$ (Fig. 2a). The proportion of resources kept or contributed to $w$ or $b$ in the social distance treatment did not differ compared to the baseline condition ( $\mathrm{p}$-values: $0.6903,0.3465,0.7949)$. Thus, the results are, on average, robust to the introduction of socially relevant information. This is to be expected as it indicates that participants' social distance is randomly distributed across groups.

\section{Figure 2: Subjects' allocations (mean)}

(a) comparison across studies

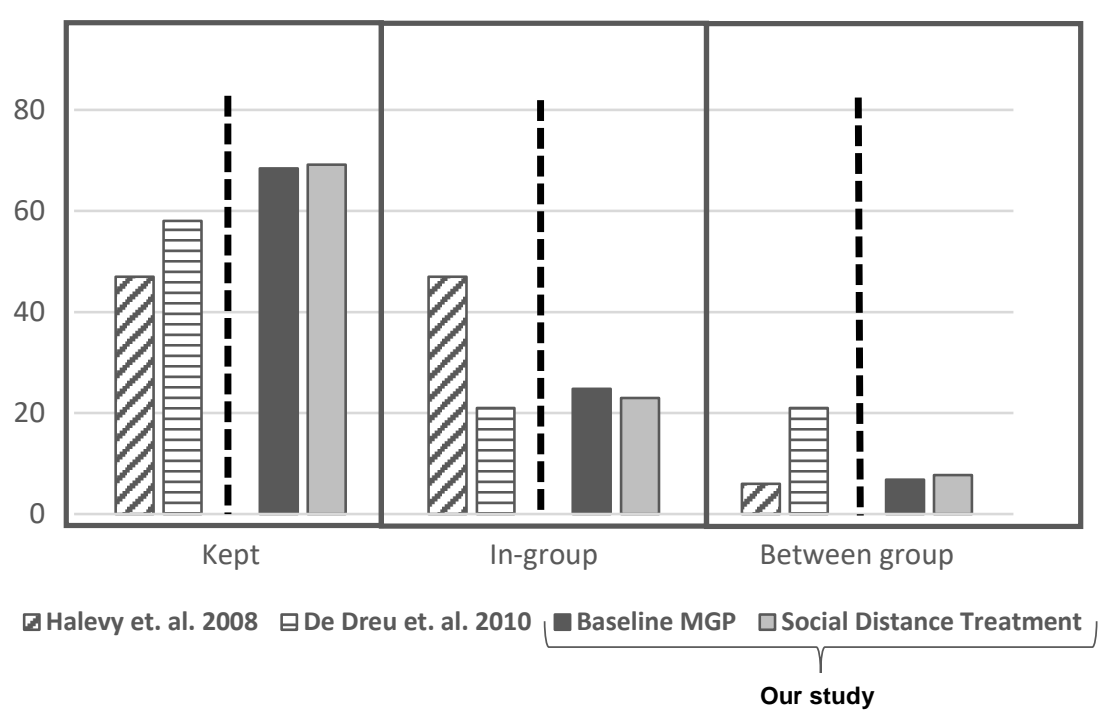

(b) our study

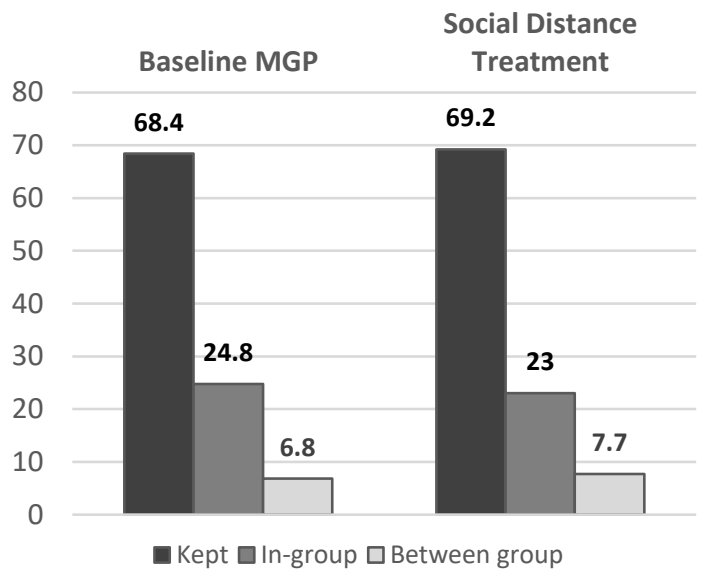

To better assess social distance's effects, we compare behavior in the baseline to behavior in categories of the treatment. We classify in- and out-group distances as "low" ("high") according to whether they fall below (above) the average for the treatment, and use categories representing the different permutations of in- and out-group pairs (Table 1).

Altruistic and parochial behavior occurs infrequently if its presence is measured as the proportion of allocations to $w$ or $b$. Subjects in the baseline and treatment on average kept $68.4 \%$ and $69.2 \%$ of their endowment, respectively (Fig. 2b). To capture parochial altruism's incidence, we employ a different measure: the percent of subjects' decisions involving some altruistic or some parochial behavior. Did 


\section{Table 1: Categories of the social distance treatment}

category name italicized; number of observations in parentheses;

social distance treatment $\mathrm{N}=402^{2}$

\begin{tabular}{l|c|c|r|r|}
\multicolumn{4}{c}{} & \multicolumn{4}{c|}{ Subject's distance to out-group members } \\
\cline { 2 - 6 } & & Low & High & \multicolumn{1}{c|}{ Any } \\
\cline { 2 - 6 } & Low & low, low $(155)$ & low, high $(77)$ & in-group low (232) \\
\cline { 2 - 6 } $\begin{array}{l}\text { Subject's } \\
\text { distance to in- } \\
\text { group members }\end{array}$ & High & high, low (80) & high, high (90) & in-group high (170) \\
\cline { 2 - 5 } & Any & out-group low (235) & out-group high (167) & $\mathrm{N}=402$ \\
\cline { 2 - 5 }
\end{tabular}

a subject keep all her resources? If not, did she allocate at least 1 [currency unit] to the $w$ or $b$ pool? Using this metric, $64.6 \%$ of subjects' decisions (baseline and treatment pooled) involved some degree of altruism or parochialism (Fig. 3a).

Comparing treatment categories to the baseline, we find that social distance to the out-group affects parochial altruism. Table A-2 summarizes these results; Fig. 3b displays them for the five categories for which we found statistically significant differences in subjects' decisions compared to the MGP baseline $(\mathrm{p}<0.05$ or $\mathrm{p}<0.10)$.

First, compared to the baseline, a lower proportion of subjects' decisions include some contribution to $w$ and/or $b$ when distance to the out-group falls below average (out-group low; $\mathrm{p}$ - value= 0.0545); similarly, a higher proportion include some contribution to $w$ and/or $b$ when that distance is above average (out-group high; $\mathrm{p}$-value=0.0938). Supporting this same relationship, a lower proportion of decisions include contributions to $b$ when distance to the in-group is above average and distance to the out-group falls below average (high, low; p-value=0.0585).

Second, when distances to both the out- and in-group fall above average (bigh, high), a higher proportion of subjects' decisions include some contribution to $w$ and/or $b$ (p-value $=0.0122)$, and in particular, a higher proportion of subjects' decisions include some contribution to $w$ ( $\mathrm{p}$-value $=0.0674$ ), with an increase in the proportion of decisions that include some contribution to $b$ at borderline statistical

\footnotetext{
2 See Table A-1 in the Appendix for further information.
} 
significance $(\mathrm{p}$-value $=0.1056)$. The combination of in- and out-group distance appears to be an important driver of the behavior. When distance to the out-group is above average, but distance to the in-group falls below average (low, high), there is no statistically significant difference in the proportion of decisions that include some contribution to $w$ and/or $b$ (p-value $=0.9497)$.

\section{Discussion}

Our results provide evidence of a relationship between social distance and parochial altruism. Parochial altruism's incidence is influenced by an individual's distance from her own in-group and the outgroup, and appears to increase when individuals are distant from both groups at the same time. Our findings are consistent with several characteristics of social distance being implicated in parochial altruism. One is the extent to which individuals experience an inter-group divide. In- and out-groups overlap to a greater extent in the two treatment categories for which we found a higher incidence of decisions involving only selfish behavior (out-group low) and a lower incidence of parochial behavior (in-group high, out-group low) than in the other categories. In other words, under conditions that produced a lower incidence of altruistic and/or parochial behavior compared to the baseline, subjects may have perceived less of a social distancebased inter-group divide (Baumgartner et al. 2014). A second characteristic is the extent of individual vulnerability. We found a higher incidence of decisions involving altruistic behavior and a borderline statistically significant positive effect on parochial behavior in the in-group high, out-group high treatment. Here, subjects' distance from in-group members is high, such that they may experience a sense of vulnerability to out-group threat. Altruistic behavior may increase under these circumstances if individuals employ it to strengthen in-group identity (Ritov \& Kogut 2017). A third characteristic is the extent to which interaction between an individual and out-group members is commonplace. We found a higher incidence of decisions involving altruistic and/or parochial behavior in the out-group high treatment; subjects here would have a lower probability of future real-world interaction with a more distant out-group. 
Figure 3: Altruistic and parochial behavior (\% of subjects' decisions)

(a) MGP baseline and social distance treatment pooled, $\mathrm{N}=852$;

(b) Categories of social distance treatment vs MGP baseline (selections)

a

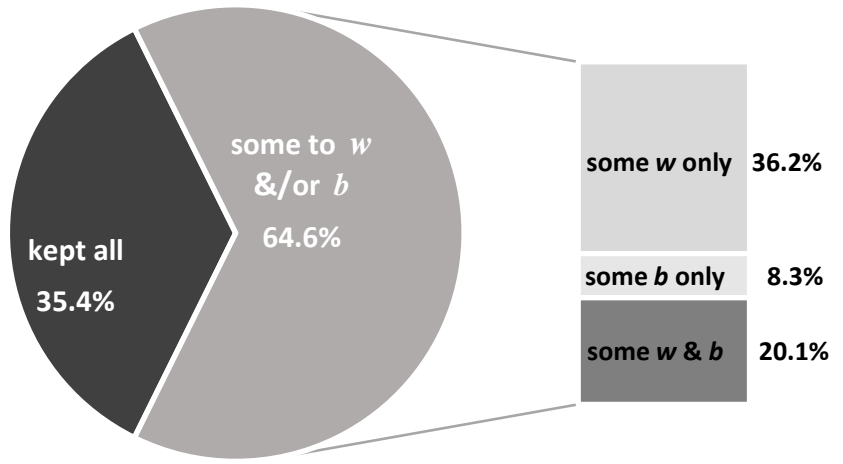

b

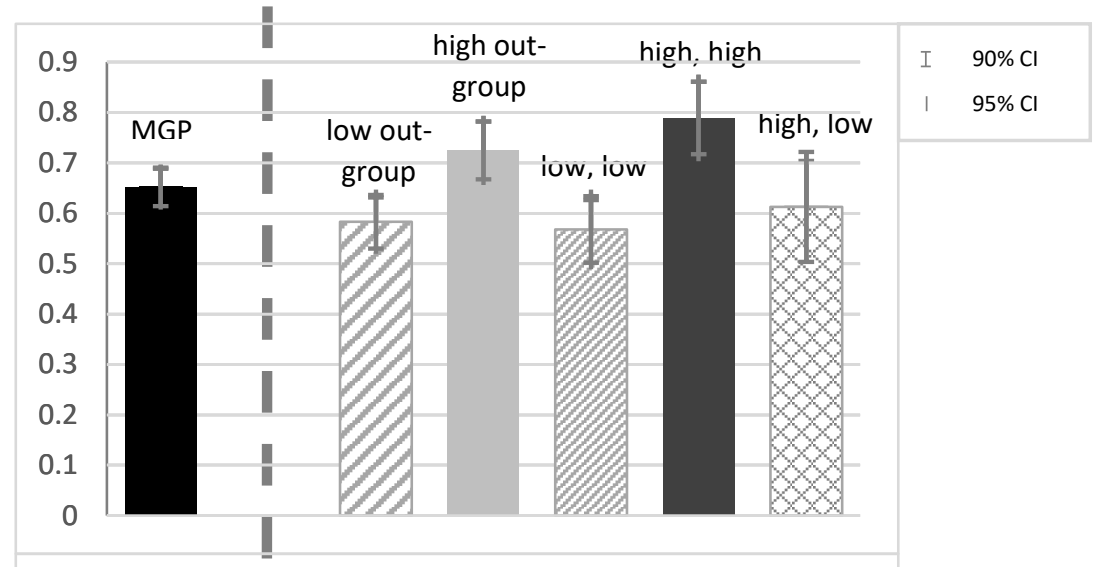

some $w$

some $b$

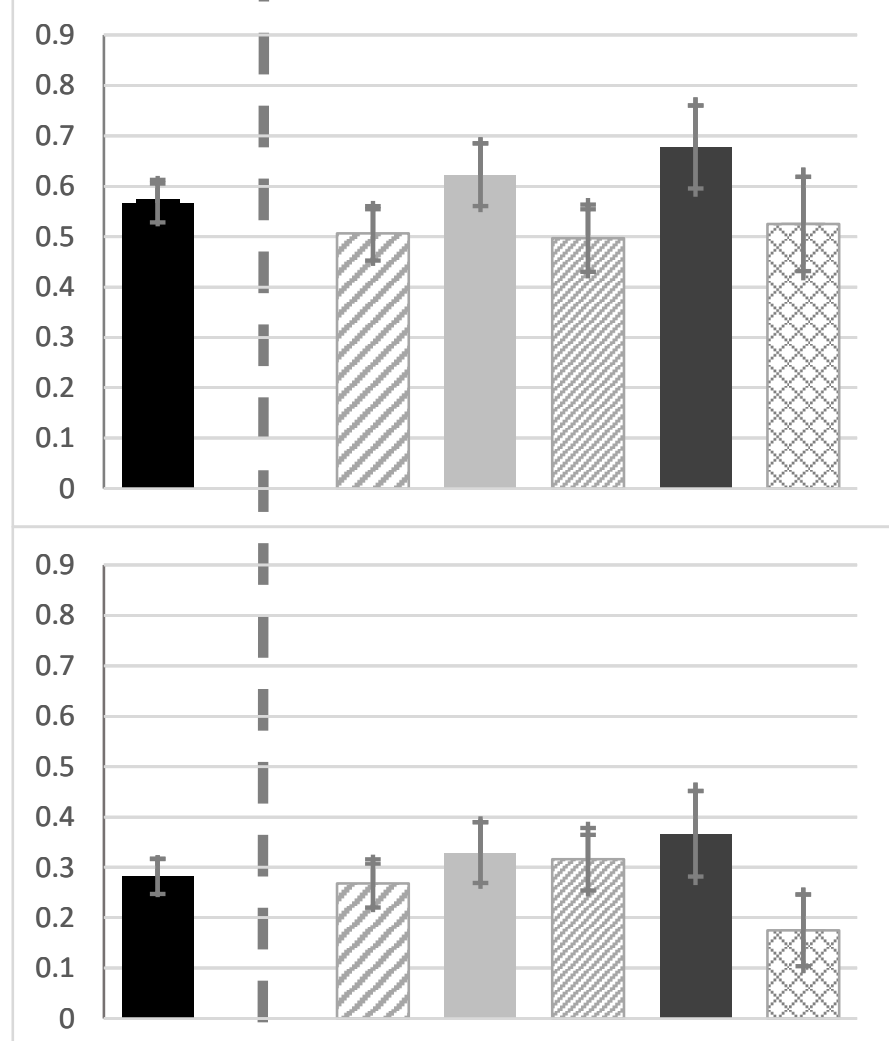


In addition, we found a lower incidence of decisions involving parochial behavior in the in-group high, outgroup low treatment; here future real-world interaction would be more likely. These results may be consistent with the possibility of successful predation stimulating parochialism and the fear of retaliation reducing it. Individuals may act to foster in-group identity in order to take advantage of socially distant out-groups with which they seldom interact. They may also behave less parochially when distant from their own ingroup but close to the out-group out of fear of retaliation (Janssen \& Bushman 2008).

\section{Conclusion}

In sum, we studied the effects of the extent of a social divide on parochial altruism. We introduced a new experimental technique to do so and used it in an IPD-MD game. We found that parochial altruism varies with social distance: higher social distance leads to a higher propensity to engage in parochial altruism, which is at its highest with high social distance to the in- and out-groups. Our methodology may help to advance the study of individual behavior in the context of inter-group interaction, particularly when researchers wish to examine the effects of the extent of the inter-group divide or differences between types of inter-group divides. A long-standing finding concerning individual behavior is that low social distance facilitates collective action (Hardin 1995). Our results indicate a potential additional pathway to groupbased individual action, one carved out by the effects of high social distance - both an individual's distance to other in-group members and to the out-group.

\section{References}

Alesina, A., Baqir, R., \& Easterly, W. (1999). Public goods and ethnic divisions. Quarterly Journal of Economics, 114(4):1243-84.

Alesina, A., Devleeschauwer, A., Easterly, W., Kurlat, S. \& Wacziarg, R. (2003). "Fractionalization," Journal of Economic Growth 8:155-94.

Baumgartner, T., Schiller, B., Rieskamp, J., Gianotti, L.R.R., \& Knoch, D. (2014). Diminishing parochialism in intergroup conflict by disrupting the right temporo-parietal junction. Social Cognitive and Affective Neuroscience 9(5):653-660.

Bernhard, H., Fischbacher, U., \& Fehr, E. (2006). Parochial altruism in humans. Nature 442(7105): 912-15.

Boehm, C. (2012). Moral origins: The evolution of virtue, altruism, and shame. New York: Basic Books. 
Choi, J.-K., \& Bowles, S. 2007. The coevolution of parochial altruism and war. Science 318(5850): 636-40.

De Dreu, C.K.W. 2012. Oxytocin modulates cooperation within and competition between groups: an integrative review and research agenda. Hormones and Behavior 61(3): 419-428.

De Dreu, C.K.W., Greer, L.L., Handgraaf, M.J.J., Shalvi, S., Van Kleef, G.A., Baas, M., Feith, S.W.W. 2010. The neuropeptide oxytocin regulates parochial altruism in intergroup conflict among humans. Science 328(5984):1408-11.

Dinesen, P. T., \& Sønderskov, K.M. 2015. Ethnic diversity and social trust: Evidence from the microcontext. American Sociological Review 80(3):550-73.

Easterly, W. \& Levine, R. 1997. Africa's Growth Tragedy: Policies and Ethnic Divisions. Quarterly Journal of Economics 112(4):1203-50.

Ember, C. R., \& Ember, M. 1992. Resource unpredictability, mistrust, and war: A cross-cultural study. Journal of Conflict Resolution 36(2):242-62.

Enos, R. D. 2017. The space between us: Social geography and politics. Cambridge: Cambridge University Press.

Filippin, A., \& Guala, F. 2017. Group identity as a social heuristic: An experiment with reaction times. Journal of Neuroscience, Psychology, and Economics 10(4):153-66.

Gat, A. 2008. War in human civilization. Oxford: Oxford University Press.

Gat, A. 2015. Proving communal warfare among hunter-gatherers. Evolutionary Anthropology 24(3):111-26.

Glowacki, L., Wilson, M.L., \& Wrangham, R.W. 2017. The evolutionary anthropology of war. Journal of Economic Behavior \& Organization. https://doi.org/10.1016/j.jebo.2017.09.014

Goette, L., Huffman, D., \& Meier, S. 2012. Impact of social ties on group interactions: Evidence from minimal groups and randomly assigned real groups. American Economic Journal: Microeconomics 4(1):101-15.

Habyarimana, J., Humphreys, M., Posner, D.N. \& Weinstein, J.M. 2007. Why Does Ethnic Diversity Undermine Public Goods Provision? American Political Science Review 101(4):709-25.

Halevy, N., Bornstein, G., \& Sagiv, L. 2008. 'In-group love' and 'out-group hate' as motives for individual participation in intergroup conflict: A new game paradigm. Psychological Science 19(4):405-11.

Hardin, R. 1995. One for all: The logic of group conflict. Princeton: Princeton University Press.

Huettel, S. A., \& Kranton, R.E. 2012. Identity economics and the brain: Uncovering the mechanisms of social conflict. Philosophical Transactions of the Royal Society B: Biological Sciences 367(1589):680-91.

Janssen, M. A., \& Bushman, C. 2008. Evolution of cooperation and altruistic punishment when retaliation is possible. Journal of Theoretical Biology 254(3):541-45.

Kavaliers, M., \& Choleris, E. 2017. Out-group threat responses, in-group bias, and nonapeptide involvement are conserved across vertebrates. American Naturalist 189(4):453-58.

Keuschnigg, M. \& Schikora, J. 2014. The dark side of leadership: An experiment on religious heterogeneity and cooperation in India, Journal of Behavioral and Experimental Economics 48(C):19-26.

Ma, Y., Liu, Y., Rand, D.G., Heatherton, T.F., \& Han, S. 2015. Opposing oxytocin effects on intergroup cooperative behavior in intuitive and reflective minds. Neuropsychopharmacology 40(10):2379-87.

Manson, J.H., \& Wrangham, R.W. 1991. Intergroup aggression in chimpanzees and humans. Current Anthropology 32(4), 369-390. 
McCoy, J., Rahman, T., \& Somer, M. 2018. Polarization and the global crisis of democracy. American Behavioral Scientist 62(1), 16-42.

Pandit, S. A., Pradhan, G. R., Balashov, H., \& Van Schaik, C. P. 2016. The conditions favoring betweencommunity raiding in chimpanzees, bonobos, and human foragers. Human Nature 27(2):141-59.

Petersen, R. D. 2001. Resistance and rebellion: Lessons from Eastern Europe. Cambridge: Cambridge Univ Press.

Ritov, I., \& Kogut, T. 2017. Altruistic behavior in cohesive social groups: The role of target identifiability. PLOS ONE, 12(11), e0187903. https://doi.org/10.1371/journal.pone.0187903

Rueda, D. 2017. Food comes first, then morals: redistribution preferences, parochial altruism, and immigration in Western Europe. Journal of Politics 80(1):225-39.

Sambanis, N., Schulhofer-Wohl, J., \& Shayo, M. 2012. Parochialism as a central challenge in counterinsurgency. Science 336(6083):805-8.

Schaub, M. 2017. Threat and parochialism in intergroup relations: lab-in-the-field evidence from rural Georgia. Proceedings of the Royal Society B: Biological Sciences 284(1865).

Tajfel, H., Billig, M.G., Bundy, R.P., \& Flament, C. 1971. Social categorization and intergroup behaviour. European Journal of Social Psychology, 1(2):149-78.

Ten Velden, F.S., Daughters, K., \& De Dreu, C.K.W. 2017. Oxytocin promotes intuitive rather than deliberated cooperation with the in-group. Hormones and Behavior 92:164-71.

Weisel, O., \& Böhm, R. 2015. "Ingroup love" and "outgroup hate" in intergroup conflict between natural groups. Journal of Experimental Social Psychology 60:110-20.

Wilson, E. O. 1978. On buman nature. Cambridge: Harvard University Press. 


\section{Appendix}

\section{Study organization}

Approval for the study was obtained from the University's Institutional Review Board. In total, 294 subjects participated in the study: 150 in the baseline condition and 144 in the treatment condition. Most laboratory sessions were conducted with 18 subjects, each of whom made decisions in 3 games. A few sessions were conducted with 12 or 6 subjects, each of whom made decisions in 1 or 2 games. A total of 450 observations were collected in the baseline condition and 402 observations in the treatment condition (see Table A-1)

Prior to each session, potential subjects were recruited via a subject pool at the University. To be eligible to participate, potential subjects had to complete a pre-study questionnaire at least four hours in advance of the lab session. This included multiple batteries of questions to avoid giving subjects any impression regarding the focus of the experiment.

Each session proceeded as follows. Subjects arrived one by one at the lab. Upon arrival, subjects provided their subject pool identity number and drew a seat number at random. Each subject was given, in real currency, the participation fee for the session. Each session required a total number of subjects that was a multiple of six, so based on seat number, some subjects were designated alternates and not seated for the study. Researchers thanked the alternates, each kept the participation fee, and they were dismissed from the laboratory. Each subject received her/his endowment of 10 [currency units], in real currency, and was then seated in isolation in a separated booth, with location in the laboratory determined using the seat number.

Subjects' seat numbers also functioned to randomly assign them to the in- and out-groups of the minimal group paradigm set-up. Specifically, each seat already had an instruction document. The document told the subject that s/he was a member of Triangle group or Circle group according to the seat number. The instruction document explained the game. It also provided a worksheet that subjects were required to 
complete in advance of participating in the first game of the session, in order to ensure that they understood the payoff structure of the game. To avoid anchoring of subjects' perception of what decision might be appropriate in the game, subjects had to provide numbers of their own to fill in the worksheet examples. The researchers and research assistants circulated through the lab and verified that each subject correctly calculated the pay-offs.

There was no contact or communication between subjects before or during the experiment between the subjects; each remained seated in isolation. No feedback was provided between games and the instruction document made clear that subjects would be matched with new in- and out-group members in each subsequent game, so there was no learning. At the end of the session, researchers calculated subjects' earnings and paid each subject individually in her/his booth. Subjects were released from the laboratory upon receiving the payment and left one by one.

\section{The Minimal Group Paradigm baseline condition}

At the beginning of each game, researchers or research assistants distributed decision sheets to the subjects by hand, following the same order, starting from the end of the laboratory opposite the researchers' work station, going down the alleys of the laboratory, and returning to the work station. At the end of each game, the decision sheets were collected by hand following the same order.

Each decision sheet contained three lines denoting the three types of possible allocations - Keep for the money kept; Pool A for the money allocated to the within group pool; and Pool B for the betweengroup pool. Each line was labeled (Keep, Pool A, or Pool B) and contained a blank line on which the subject would fill out his/her allocation decision. The decision-sheet provided a fourth line below these three, on which subjects had to do calculation verifying that their total allocations summed to ten currency units, i.e. the size of their endowment. The order in which the three lines for subjects' allocation decisions were printed on the decision sheet was randomized to avoid any default bias. Finally, the data collection 
process was intentionally not computerized to guarantee that subjects took the time to read the information sheet and to make their decisions.

\section{The Social Distance treatment condition}

We implemented the social distance treatment subtly. For each of these sessions, the study proceeded as outlined for the Minimal Group Paradigm baseline condition, but with one difference: at the beginning of each game, each subject received an information sheet along with the decision sheet. The information sheet provided information about three types of characteristics for each in-group and each out-group member: locality of origin (at the sub-provincial level), age, and sex.

The information sheets were constructed by researchers using a computerized device at the beginning of the session. After subjects arrived at the laboratory, their subject pool identity numbers were used by researchers to retrieve each subject's information from the pre-study questionnaire. Researchers used a laser printer at their work station to print the information sheets. 
Table A-1: Organization of the study

\begin{tabular}{|c|c|c|c|c|c|}
\hline \multirow[b]{3}{*}{ Experimental Condition } & \multirow{3}{*}{$\begin{array}{c}(1) \\
\text { Sessions }\end{array}$} & \multicolumn{2}{|c|}{ Per session } & \multicolumn{2}{|c|}{ Total } \\
\hline & & (2) & (3) & $($ Col. $1 \times 2)$ & (Col. $1 \times 2 \times 3)$ \\
\hline & & Subjects & Games & Subjects & Observations \\
\hline \multirow[t]{3}{*}{ Minimal group paradigm } & 7 & 18 & 3 & 126 & 378 \\
\hline & 2 & 6 & 3 & 12 & 36 \\
\hline & 1 & 12 & 3 & 12 & 36 \\
\hline Total & 10 & & 9 & $150^{1}$ & $450 \ddagger$ \\
\hline \multirow[t]{4}{*}{ Social distance treatment } & 6 & 18 & 3 & 108 & 324 \\
\hline & 1 & 18 & 2 & 18 & 36 \\
\hline & 1 & 12 & 3 & 12 & 36 \\
\hline & 1 & 6 & 1 & 6 & 6 \\
\hline Total & 9 & & 9 & $144^{2}$ & $402 \S$ \\
\hline
\end{tabular}

\footnotetext{
1 Three individuals, each with 3 observations, had previously participated in the treatment condition, and so we exclude their observations (9) when running the analysis. This means that the analysis uses 441 of the 450 observations.

2 Two of these participants are the same individual after discovering this individual's double participation, we drop the observations from his second participation (3) when running the analysis. This means that the analysis uses 399 of the 402 observations.
} 
Table A-2: \% of subjects' decisions, social distance treatment by category vs. Minimal Group Paradigm baseline

Mann-Whitney tests. Sign of effect is above cell diagonal; p-value below the diagonal. Statistical significance indicated by shading: white \& bolded, $\mathrm{p}<0.05$; white, $\mathrm{p}<0.10$.

Number of decisions in parentheses.

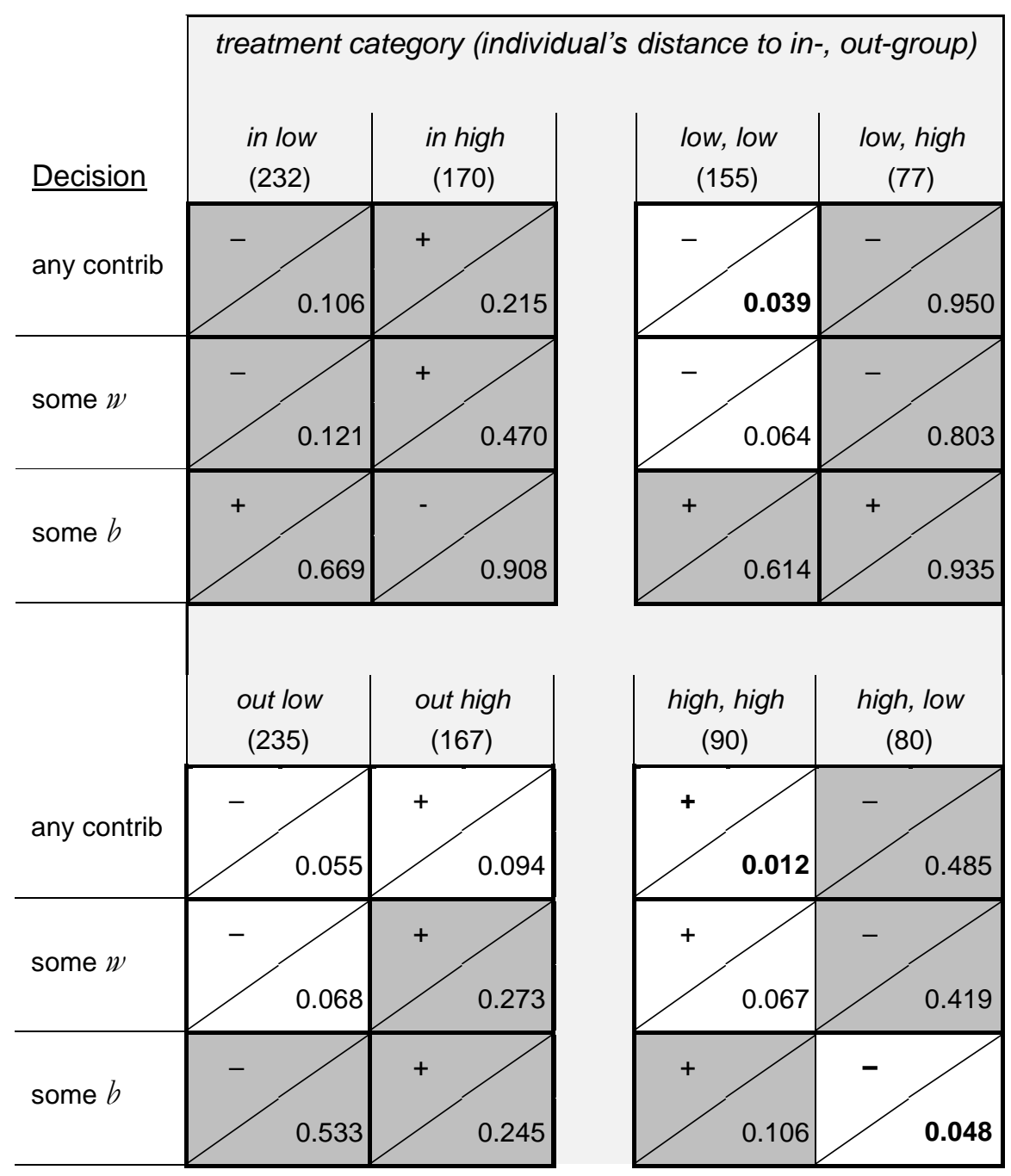

